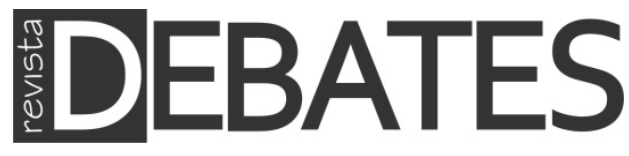

\title{
Os jovens estão mais assertivos politicamente no Brasil? Uma análise da cultura política
}

\author{
Are young people more politically assertive in Brazil? A political \\ culture analysis
}

\author{
Marcello Baquero \\ Rute Vivian Angelo Baquero \\ Jennifer Azambuja de Morais
}

\section{Resumo}

Quase 80 milhôes de brasileiros estão conectados de alguma forma via internet e redes sociais. A mídia digital tem aumentado a visibilidade de grupos tradicionalmente esquecidos, como é o caso dos jovens. Enquanto, para alguns, deve ser comemorada, para outros, existem duvidas em relação a se essa tecnologia per se poderia alavancar mudanças sociais e políticas significativas, produzindo uma nova cultura política juvenil. No caso do Brasil, o uso da internet reflete as muitas contradiçóes e complexidades de uma sociedade, na qual há uma assimetria entre desenvolvimento econômico e desigualdades sociais. Neste artigo, examinamos a influência do uso das NTIC's na formação da cultura política brasileira. Utilizamos dados de pesquisas probabilísticas realizadas em três cidades do Sul e Brasil (Porto Alegre, Florianópolis e Curitiba) em 2015 e 2016. Os resultados sugerem que as NTIC's ainda não se constituem em forte agente de socialização política, prevalecendo práticas tradicionais.

\section{Palavras-chave}

Juventude; NTIC's; Socialização Política; Cultura Política.

\begin{abstract}
Almost 80 million of Brazilians are connected in some way through the internet and social networks. The digital media has increased the visibility of groups that traditionally have been forgotten, as is the case of the youth. While for some the use of these technologies should be commemorated, for others doubts exist related to the possibility of these technologies generate social changes producing a new youth's political culture. In Brazil, the use of internet reflects the many contradictions and complexities of a society in which there is an asymmetry between economic development and social inequalities. This article examines the influence of the use of the NTIC's in the structuring of the Brazilian political culture. We utilized data from a probabilistic survey research conducted in three cities in the South of Brazil (Porto Alegre, Florianopolis and Curitiba) in 2015 and 2016. The results suggest that the NTIC's have not yet become strong agents of political socialization.
\end{abstract}

\section{Keywords}

Youth; NTIC’s; Socialização Política; Cultura Política. 


\section{Introdução}

A construçáo de uma democracia plena (procedimentos e substância) requer, entre outros fatores, cidadãos civicamente empoderados e com predisposiçóes atitudinais e comportamentais para se envolver com política. Tais atitudes e comportamentos se constituem em fatores essenciais para que um sistema político tenha legitimidade não só jurídica, mas também no âmbito da sociedade. Quando as pessoas acreditam no sistema político, nas suas instituiçóes e nos representantes eleitos, a legitimidade é uma consequência natural, possibilitando que, mesmo em épocas de crises econômicas e políticas, a estabilidade institucional não seja ameaçada.

Embora a dimensão eleitoral pareça estar consolidada, apesar das deficiências institucionais que ainda prevalecem, as democracias emergentes enfrentam atualmente dois desafios produzidos pela modernidade e as configuraçóes pósmodernas com as quais convivem. O principal desafio que as democracias emergentes enfrentam é gerar inclusão social e realizar redistribuição da riqueza com base em princípios de equidade. O segundo desafio é estabelecer uma cultura política crítica e participativa. Nesse sentido, é fundamental examinar o papel do cidadáo no processo político para além da dimensão puramente institucional.

Nos últimos anos, se observa, no Brasil e na América Latina, uma erosão gradual da democracia no seu sentido social, uma vez que as necessidades básicas de grande maioria da população não têm sido atendidas. A consequência tem sido o sentimento de abandono da parte do Estado pelos cidadáos. Tal situação tem se materializado na ocorrência, cada vez mais frequente, de conflitos entre Estado e sociedade, resultando na emergência de um sistema político híbrido, no qual existe uma assimetria entre legitimidade formal e legitimidade conferida pelos cidadãos.

Um setor particularmente afetado por esse processo é a juventude, cujas crenças políticas, de acordo com pesquisas de campo realizadas nos últimos anos (BAQUERO e MORAIS, 2015 e 2016), têm sido preponderantemente negativas. Com o advento das novas tecnologias de informação e comunicação (NTIC’s), a desilusão das novas geraçôes com as instituiçôes democráticas tem ficado explícita, uma vez que não as consideram canais de expressão de suas demandas. Assim, a juventude brasileira, em grande parte composta por "nativos digitais", cada vez mais tem se utilizado dos recursos dessas tecnologias - a internet e suas redes sociais - para expor e arregimentarem adeptos para suas causas.

Nesse contexto, este artigo visa problematizar como os jovens no Sul do Brasil estão ressignificando seu papel como sujeitos políticos num contexto de legitimidade procedimental e avanços nas tecnologias de informação e comunicação (TIC's), 
concomitantemente com o aumento do ceticismo político e descrença nos aspectos formais da democracia representativa, bem como qual o tipo de cultura juvenil que está se desenhando para o futuro.

A hipótese que propomos testar é de que: apesar da proliferação das NTIC's, não parece estar em andamento uma modificação significativa da cultura política dos jovens no Sul do Brasil, que permanece passiva, submissa e pouco participativa.

$\mathrm{O}$ artigo está estruturado em quatro partes, além da introdução. Na primeira parte, examinamos como a juventude é vista atualmente. Na segunda parte, analisamos o impacto das NTIC's na juventude contemporânea. Na terceira parte identificamos os condicionantes históricos na socialização e estruturação de uma cultura política juvenil no Sul do Brasil. Na quarta parte, analisamos empiricamente os dados da pesquisa "Democracia, mídias e capital social: Um estudo comparativo de socialização política dos jovens no Sul do Brasil”, realizada em escolas públicas e privadas, com alunos de 13 a 24 anos, nas cidades de Porto Alegre (690 jovens), em 2015, Florianópolis (571 jovens) e Curitiba (774 jovens), em 2016.

\section{Juventude}

Os jovens geralmente são visualizados como um problema ou uma solução e não como sujeitos protagônicos de uma sociedade. De maneira geral, os jovens são marginalizados em discursos e análises sociais mais amplos, que desconsideram sua importância, tanto no sentido quantitativo $(17,24 \%$ da população brasileira, conforme senso do IBGE de 2010) quanto no qualitativo, como sujeitos capazes e dispostos a promover mudanças, movidos por causas sociais e determinados ideais, inseridos, também, no contexto de mudanças tecnológicas que caracterizam o século XXI.

Um dos fatores que tem afetando significativamente os setores mais jovens da população é o desemprego. Tokman (1996) observa que, quando há crescimento econômico e as taxas de desemprego baixam, tal fenômeno demora mais tempo para ocorrer junto aos jovens. Ao mesmo tempo, quando a economia passa a sofrer abalos, e as taxas de desemprego sobem, os jovens são os primeiros a sentir tais efeitos. Além desses elementos, há que se destacar a precarização do trabalho, impactando, de forma significativa, na juventude. Há que se referir, também, que tais impactos possuem um importante recorte em termos de situaçáo socioeconômica dos jovens, com aqueles provenientes de classes mais abastadas em condiçóes que lhes permitem obter melhores oportunidades. 
74 | Marcello Baquero, Rute Baquero e Jennifer Morais

Desse modo, na ocorrência de crises econômicas, são os estratos compostos pelos jovens que sentem a falta de oportunidades, incerteza em relação ao futuro e desilusáo com o estado das coisas. Um dos principais problemas resulta da desigualdade social, assim como a distribuiçẫo de renda influi em todas as dimensóes da estrutura social (por exemplo, em saúde e em educação). Tais disparidades podem ser verificadas entre os jovens, que possuem "circuitos de vida" diferentes de acordo com seus estratos sociais; plasmados em oportunidades diferentes entre as camadas sociais, afetam o tipo de cultura política que se estrutura no país.

Observa-se também, no Brasil, no que diz respeito à influência da família, que a permanência dos jovens junto a suas respectivas famílias tem aumentado, o que pode ter relaçáo com as dificuldades em termos de inserção no mercado de trabalho. Um fenômeno que chama a atenção é o número crescente de mulheres como "chefes de família”, o que é causado pelas dificuldades que muitos homens têm encontrado no mercado de trabalho, fato que leva muitos deles, inclusive, a abandonar suas famílias.

Em relação a uma área chave para os jovens como é a educação, a despeito dos investimentos quantitativos que têm sido realizados, os resultados qualitativos estáo aquém das necessidades do país. Além disso, mesmo na educação pública, verificamse diferenças significativas na distribuição de recursos, face à integração deficiente entre os estados e municípios, responsáveis pela demanda da educação básica (SCHWARTZMAN, DURHAM e GOLDEMBERG, 1995).

Nesse cenário, argumentamos ser imperativo que a juventude, no processo de construçáo democrática em andamento, seja considerada como ator central no planejamento e aplicação de políticas públicas. Dentre os pontos a serem priorizados estão tanto os aspectos materiais essenciais (educação, moradia, uma melhor qualidade de vida, diminuição de disparidades, a saúde e mercado de trabalho), quanto os aspectos mais substantivos da democracia (ampliaçáo dos direitos civis e liberdades políticas e possibilitar um efetivo engajamento dos jovens na política). No entanto, para produzir uma juventude interessada e participativa no futuro, é preciso que se institucionalizem bases sólidas de fomento dos valores democráticos por meio de um processo de socialização política direcionada à construção de cidadáos jovens assertivos e participativos. Uma ferramenta considerada estratégica para alcançar tal objetivo seriam as NTIC's.

As NTIC's, sobretudo a internet, têm possibilitado a construção de comunidades virtuais, dando visibilidade às demandas e interesses da juventude, sendo que $35 \%$ dos jovens brasileiros se consideram engajados no ativismo digital, 
enquanto $18 \%$ estão distantes do tema e $41 \%$ são imparciais (FUNDAÇÃO TELEFÔNICA VIVO, 2014). E ainda, segundo os dados, ativistas ou não, 41\% dos jovens já assinaram abaixo-assinados e petiçóes, 38\% participaram de protestos fora do ambiente virtual e $31 \%$ dos jovens dizem terem participado de debates sobre temas relevantes para a sociedade. Dessa forma, que os jovens, cada vez, mais utilizam a internet como mecanismo de obtenção de informaçóes que afetam seu comportamento político. A questão que se coloca para discussão, entretanto, é: há, de fato, condiçôes para que uma nova cultura política juvenil se materialize no Brasil? Antes de responder a esta indagação, discutimos como as NTCI's impactam a juventude contemporânea.

\section{O Impacto das NTIC's nos jovens}

Os avanços tecnológicos ocorridos nas últimas cinco décadas vêm impactando os setores público e privado, no contexto social, político e econômico. As NTIC's, desenvolvidas desde meados dos anos 1970, no contexto da Revolução Informacional (CASTELLS, 2007), agilizam e horizontalizam a comunicação. Para Targino (1995), essa revolução tecnológica provocou profundas alteraçôes na configuraçáo social, através da descentralização da economia, alteração de práticas culturais, redefinição do trabalho e democratização da informação. Diferente das TIC's, as NTIC's priorizam a interatividade, articulam várias formas de armazenamento e difusão da informação, além de ultrapassarem o modelo tradicional de comunicação um-todos e adotarem a conversação todos-todos.

Nessa evolução das TIC's, a internet é a ferramenta central, na medida em que interligou não só computadores, como também as pessoas através de seus sites de redes sociais. Desse modo, é inquestionável a influência da internet em geral, e das redes sociais em particular, na vida das pessoas e, com maior frequência, dos jovens, visto que, além de atividades rotineiras estarem sendo realizadas através da internet (como transaçóes bancárias, busca de informação, entre outras), estão se estabelecendo novas formas de interação social.

A criação da internet teve início na década de 1960 nos Estados Unidos, motivada por interesses militares de defesa e segurança e, provavelmente, não se imaginava a amplitude que teria, chegando a ser um fenômeno global ${ }^{1}$. Uma definição técnica do termo internet, encontrada em dicionários, especifica-a como uma rede global de computadores interligados, sendo composta por milhôes de redes

\footnotetext{
${ }^{1}$ Para uma abordagem histórica, ver Castells (2003).
} 
particulares (desde residências até empresas, universidades e órgãos do governo). A internet é considerada um fenômeno pela possibilidade de acesso à informação, além de recursos que facilitam a comunicação, como e-mails e redes sociais.

Uma definição mais pontual é proposta por Castells (2003), postulando que a internet é um meio de comunicação que permite, pela primeira vez, a comunicação de muitos com muitos, sobre o qual se baseia uma nova forma de sociedade: a sociedade em rede. Com base nessa conceituação, chega-se à perspectiva da sociedade em rede, que basicamente é a sociedade conectada, ou seja, a sociedade interagindo, gerando e consumindo muitas informaçóes. A internet, para além dessas funçôes, também contribui para a formação de redes sociais que se materializam em comunidades virtuais. No caso dos jovens ${ }^{2}$, isso é mais marcante, uma vez que essa faixa etária é extremamente interativa, com muita facilidade de se apropriar de NTIC's e novos espaços de interação virtual. Neste sentido, apesar da universalidade de acesso da televisão, a internet torna-se uma mídia com rápida expansão entre os jovens, e, da mesma forma que a televisão, pode promover a identidade cultural dos jovens, contribuindo para o processo de construçáo de valores sociais.

Essa rápida expansão, resultado da constituição de sites de redes sociais, como Facebook, Orkut, Google Plus, Twitter, Youtube, MySpace, Whats App, blogs e fóruns em geral proporcionam entre os jovens uma ampla interaçáo, além de uma rápida propagação da informação. Embora esses sites atuem como suporte para as interaçôes que constituirão as redes sociais, "eles não são, por si, redes sociais. Eles podem apresentá-las, auxiliar a percebê-las, mas é importante salientar que são, em si, apenas sistemas. São os atores sociais que utilizam essas redes, que constituem essas redes" (RECUERO, 2009, p. 103). Conforme Machado e Tijiboy (2005, s/ p.), esses sites são os programas que funcionam como mediadores sociais que, por sua vez, favorecem a criação de redes de relacionamento "através de espaços onde o usuário pode juntar pessoas do seu círculo de relacionamento, conhecer outras que compartilhem os mesmos interesses e discutir temas variados, construindo diferentes elos entre os 'eus' privado e público".

É nesse contexto que as redes sociais têm se tornado um dos meios mais populares de compartilhamento de informaçôes, de relacionamentos pessoais e a base sobre a qual novas identidades coletivas anônimas são formadas. Segundo Garton, Haythornthwaite e Wellman, (1997), uma rede social se naturaliza quando uma rede de computadores conecta uma rede de pessoas e organizaçóes. Para Aguiar (2007), os

\footnotetext{
${ }^{2}$ Segundo Prensky (2006), os jovens são considerados os "nativos digitais”.
} 
padrôes de relacionamento encontrados nessas redes diferem substancialmente dos encontrados nas estruturas de redes conhecidos pela literatura desenvolvida nas redes sociais fora do mundo virtual.

Dessa forma, para Recuero (2009), uma rede é uma metáfora para observar os padrôes de conexão de um grupo social, a partir das conexôes estabelecidas entre os diversos atores. A abordagem de rede tem, assim, seu foco na estrutura social, onde não é possível isolar os atores sociais (pessoas, instituiçôes ou grupos, ou seja, os nós da rede) e nem suas conexóes (interaçóes ou laços sociais). Em termos gerais, as conexões em uma rede social são constituídas pelos laços sociais que, por sua vez, são formados através da interação social entre os atores. De certo modo, são as conexôes o principal foco do estudo das redes sociais, pois é sua variação que altera as estruturas desses grupos (RECUERO, 2009).

Com relaçáo às interaçóes sociais, para Primo (2003), existem duas formas de interação: (1) a interação mútua e (2) a interação reativa. Interação mútua é aquela caracterizada por relaçóes interdependentes e processos de negociação, em que cada interagente participa da construção inventiva e cooperada da relação, afetando-se mutuamente; enquanto a interação reativa é limitada por relaçóes determinísticas de estímulo e resposta. A interação realizada a partir das redes sociais é caracterizada não apenas pelas mensagens trocadas (o conteúdo) e pelos integrantes da rede que se encontram em contextos geográfico, social, político e temporal diferentes. Tal interaçáo é caracterizada, também, pelo relacionamento que existe entre os integrantes. Trata-se de uma construção coletiva, inventada pelos indivíduos que agem durante o processo, que não pode ser manipulada unilateralmente nem prédeterminada (PRIMO, 2003).

Nesta perspectiva de interaçóes sociais realizadas através dos sites de redes sociais, a internet tem proporcionado a existência de uma sociedade em rede, em que a circulaçáo de informaçôes, economia e organizaçôes estão constantemente correlacionadas em uma interação que proporciona a interdependência (CASTELLS, 2007). O autor defende que a internet se transforma em um meio de fortalecimento dos laços de interação social vividos no mundo fora do virtual e proporciona a expansão dos mesmos dentro do mundo virtual, aos quais ele denomina comunidades virtuais.

Rheingold (1995) foi um dos primeiros autores a efetivamente utilizar o termo "comunidade virtual”, na área da comunicação. Para ele, as comunidades virtuais são agregados sociais que "surgem da Rede [Internet], quando uma 
quantidade suficiente de gente leva adiante essas discussóes públicas durante um tempo suficiente, com suficientes sentimentos humanos, para formar redes de relaçôes pessoais no ciberespaço" (1995, p. 20).

Com base nessa definição, Recuero (2009) considera que os elementos formadores da comunidade virtual seriam: as discussóes públicas, as pessoas que se encontram e reencontram, ou que ainda mantêm contato através da internet (para levar adiante a discussão), o tempo e o sentimento. Esses elementos, combinados através do ciberespaço, poderiam ser formadores de redes de relaçóes sociais, constituindo-se em comunidades.

Portanto, as comunidades virtuais se fortalecem a partir das redes sociais constituídas dos Sites de Relacionamento, e as relaçóes experimentadas dentro dessas comunidades caracterizam outra forma de sociabilidade, pois possuem características específicas proporcionadas pelo mundo virtual. Dessa forma, se ampliam os vínculos sociais e criam-se as condiçóes para uma disseminação de "comunicação de massa com a penetração da comunicação pessoal” (CASTELLS, 2007, p. 446). Para Thompson e Hickey (2011), as NTIC's agem de forma diferente dos outros meios de socialização terciários - televisão e outros agentes de mídia, como rádio, jornais e etc. -, isto porque as NTIC's não favorecem somente a transmissão de informaçôes, mas também isolam o indivíduo.

Percebe-se, com esses apontamentos, que as NTIC's, além de se constituírem um fenômeno da modernidade, influenciam a vida das pessoas, potencializando as formas de agir e intervir socialmente, principalmente dos jovens. Para esses jovens, conhecidos como nativos digitais, por terem nascido na época onde, praticamente, tudo está conectado, a internet se apresenta ilimitada em suas capacidades de informar e comunicar. Os avanços tecnológicos permitem que o jovem fique grande parte de seu dia conectado à internet, seja pelo computador pessoal ou tablet, como também pelo celular. Nesse sentido, Sales (2011) ressalta que as NTIC's, com enfoque para juventude, têm influenciado nossas práticas sociais, nossas vidas e o cotidiano. Segundo a autora, falar de juventude e das NTIC's implica em percorrer um território sempre em fluxo, "a linguagem, por exemplo, é ressignificada pelos grupos juvenis e pela internet, o que pode ser percebido nos símbolos e palavras que ganham novos sentidos" (SALES, 2011, p. 2).

Essa difusão, principalmente da internet, computador e celular, está provocando mudanças na forma e no resultado da sociabilidade não só por possibilitar um número incalculável de relaçóes num curto período de tempo, mas também por proporcionar diferentes formas de interagir com essas novas relaçôes. Os 
efeitos do uso desses meios de comunicação, em especial a internet e os sites de redes sociais, são estudados por duas teorias: efeitos negativos e teoria da mobilizaçáo.

A primeira teoria, dos efeitos negativos, trabalha com a perspectiva de que os meios de comunicação interferem de forma negativa no aprendizado dos assuntos públicos, diminuindo a confiança no governo e na participação política (PATTERSON, 1980 e 1998; MERVIN, 1998; NEGRINE, 1996; CAPELLA e JAMIESON, 1997; PUTNAM, 1995). A segunda teoria, a teoria da mobilização, acredita no poder de mobilização política das mídias (NORRIS, 1999; NEWTON, 1999; MATOS, 2007; RECUERO, 2009).

O que náo tem ficado claro é a forma como os efeitos positivos ou negativos dessas NTIC’s auxiliam ou não na estruturação de uma cultura política juvenil diferente das do passado. Na próxima seção, analisamos a construçâo da cultura política no Brasil.

\section{Tipo de cultura politica no Sul do Brasil e socialização politica}

Há um consenso na bibliografia recente de que a terceira onda de democracia possibilitou o fortalecimento da democracia representativa globalmente. Agências de avaliação democrática têm colocado o Brasil como um dos países que mais avançou na dimensão institucional. Entretanto, apesar desse importante avanço, a democracia não se restringe unicamente aos aspectos formais, sendo necessário levar em conta a influência da história e da cultura na formatação de uma cultura política.

Nessa perspectiva, fatores como a desigualdade econômica, os déficits de investimentos sociais e a presença da corrupção institucionalizada afetam o tipo de cultura política que se manifesta num determinado momento, onde crenças e valores dos jovens em relação à política não se mostram suficientemente sólidos para consolidar uma democracia plena.

Examinar, portanto, os constrangimentos que inibem a materialização de uma cultura política assertiva e participativa da juventude assumem centralidade no momento atual do Brasil. A história recente do Brasil tem mostrado que as instituições por si só não são suficientes para produzir cidadãos críticos e participativos. A este respeito, Dahl (1992, p. 48) argumenta que "as práticas e instituiçóes da democracia moderna parecem estar falhando em produzir cidadãos 'bons-o-suficiente'”. O elo que estaria faltando se refere ao tipo de cultura política existente. 
No âmago da teoria da cultura política está o princípio da congruência entre cultura e instituiçóes (ALMOND e VERBA, 1989). Quando essa congruência não existe, a probabilidade de (re)emergir práticas políticas deletérias para $\mathrm{o}$ desenvolvimento democrático é elevada, sendo as principais: personalismo, patrimonialismo, individualismo, paternalismo e clientelismo. Esses fatores contribuem na constituição de uma cultura política híbrida, onde atitudes e comportamento dos cidadáos não são consistentes. Por exemplo, embora exista, por parte dos jovens, um apoio difuso aos princípios democráticos, seu comportamento é de ceticismo, hostilidade e desconfiança em relação às instituiçóes políticas e seus representantes. Nesse contexto, a materialização de uma cultura política ideal ou cívica, proposta por Almond e Verba (1989), dificilmente ocorreria. Principalmente pelo fato de que, em países como o Brasil, o legado político não propiciou a construção de uma cultura política com essas características virtuosas.

Esse paradoxo, por várias décadas, não foi considerado importante, uma vez que a abordagem institucional predominou na Ciência Política, colocando os estudos sobre a constituição de uma cultura política em papel secundário. Foi o desempenho deficiente das democracias da terceira onda que propiciou o retorno de estudos sob a ótica da cultura política. Tornava-se pertinente explicar a incongruência entre instituições formais e os valores e comportamentos dos jovens cidadãos em relação à política, uma vez que o apoio difuso à democracia é inconsistente com o apoio especifico ao desempenho democrático (SHIN, 2006; MOISÉS, 1995, 2010).

Recentes estudos (DALTON e WELZEL, 2014) apresentaram uma perspectiva diferente a respeito das atitudes e comportamentos necessários e congruentes com um regime democrático. Desde a publicação da obra The Silent Revolution, de Iglehart (1977), institucionalizou-se uma linha de análise que argumentava que, em sociedades materialmente resolvidas (moradia, educação, saúde e segurança), as geraçôes beneficiadas por esse tipo de sociedade produziam valores de natureza pósmaterialista. Nessa direção, os estudos sobre cultura política passaram a avaliar a existência de valores pós-materialistas em sociedades emergentes. Embora tivesse sido constatada a emergência desses valores em parte da população, a prática e comportamento político continuavam a se dar numa dimensão preponderantemente materialista, indicando, portanto, que não houve modificação na cultura política.

Pensamos que tal resultado deriva da negligência dos estudos em relação à influência da história, dos valores e das normas tradicionais na estruturação de uma cultura política. A existência de valores pós-materialistas, conjugada a uma situação 
de não solução da dimensão material continuou a gerar uma democracia hibrida e incompleta.

Esforços para examinar a constituição da cultura política de uma sociedade, para além da dimensão proposta por Almond e Verba (1989), que consideravam que os cidadãos deveriam ser submissos e leais, foi proposta por Dalton e Welzel (2014) com base no argumento de que se observa, globalmente, uma tendência crescente nas populaçôes na direção de internalizar valores assertivos e de auto-expressão. Esses valores, em parte, estariam sendo gerados pela influência das NTIC's, que estariam estimulando cidadãos mais críticos e participativos não só em sociedades pósmaterialistas, mas igualmente em sociedades emergentes. A presença de cidadãos mais politizados, portanto, seria um ingrediente fundamental para o fortalecimento da democracia.

A base sobre a qual esse argumento se assenta diz respeito à constatação de que a percepção da democracia no mundo contemporâneo, por parte das pessoas, estaria mudando, possibilitando que os cidadãos exercitem a liberdade de governar suas próprias vidas (auto-expressão). Tal situação seria o resultado da crescente insatisfação e rejeição das instituições de mediação política que não atendem aos interesses de grupos tradicionalmente deixados à margem das políticas públicas.

A existência de cidadãos assertivos teria um impacto virtuoso no fortalecimento da democracia, pois, além de fomentar o desenvolvimento humano (SEN, 1999), auxiliaria no empoderamento dos jovens. As características dos modelos de cultura política (1) de cidadania leal e submissa e (2) de cidadania assertiva, elaborado por Dalton e Welzel, é apresentado no Quadro 1. 
Quadro 1 - Aspectos da Cidadania Leal e Asserticva

\begin{tabular}{|c|c|c|}
\hline Domínio & Cidadania Leal (Allegiant) & Cidadania Assertiva (Assertive) \\
\hline $\begin{array}{l}\text { Prioridades de } \\
\text { Valores }\end{array}$ & $\begin{array}{c}\text { Prioridades dos resultados das } \\
\text { políticas públicas; ênfase na ordem e } \\
\text { na segurança; limitação na ênfase da } \\
\text { expressão e participação; predominam } \\
\text { valores materialistas de proteção }\end{array}$ & $\begin{array}{c}\text { Prioridades nas demandas; ênfase na } \\
\text { expressão e na participação; limite na } \\
\text { segurança e na ordem; prevalência nos valores } \\
\text { pós-materialistas/emancipatórios }\end{array}$ \\
\hline $\begin{array}{l}\text { Orientação à } \\
\text { autoridade }\end{array}$ & $\begin{array}{c}\text { Deferência à autoridade na família, } \\
\text { no trabalho e na política }\end{array}$ & $\begin{array}{c}\text { Distanciamento da autoridade na família, no } \\
\text { trabalho e na política }\end{array}$ \\
\hline $\begin{array}{c}\text { Confiança } \\
\text { Institucional }\end{array}$ & Confiança nas instituições & Pouca confiança nas instituiçóes \\
\hline $\begin{array}{c}\text { Apoio à } \\
\text { Democracia }\end{array}$ & $\begin{array}{l}\text { Apoio aos princípios da democracia e } \\
\text { às suas práticas (satisfação cidadã) }\end{array}$ & $\begin{array}{c}\text { Apoio aos princípios da democracia, mas } \\
\text { baixo apoio às suas práticas (insatisfação } \\
\text { cidadã) }\end{array}$ \\
\hline $\begin{array}{l}\text { Noção de } \\
\text { democracia }\end{array}$ & $\begin{array}{l}\text { Combinaçáo de noçóes voltadas para } \\
\text { as demandas (participação) com } \\
\text { noçóes voltadas para os resultados } \\
\text { (democracia como uma ferramenta } \\
\text { para atingir bens sociais) } \\
\end{array}$ & $\begin{array}{l}\text { Noções de democracia relacionadas as } \\
\text { demandas se tornam dominantes }\end{array}$ \\
\hline $\begin{array}{l}\text { Ativismo } \\
\text { político }\end{array}$ & $\begin{array}{l}\text { Voto e outras formas convencionais } \\
\text { de atividades que legitimam o regime }\end{array}$ & $\begin{array}{c}\text { Elevada afinidade com açóes não-violentas e } \\
\text { desafiadoras da elite política estabelecida }\end{array}$ \\
\hline $\begin{array}{l}\text { Consequências } \\
\text { sistêmicas } \\
\text { esperadas }\end{array}$ & \multicolumn{2}{|c|}{ Governança mais efetiva e responsável? } \\
\hline
\end{tabular}

Fonte: Dalton e Welzel, 2014.

A noção de assertividade proposta por Dalton e Welzel caracteriza os cidadãos como sujeitos predispostos a se engajar na arena política para manifestar suas demandas com a expectativa de que não só serão ouvidos, mas serão atendidos. Se tal cenário pode ser observado em sociedades democraticamente consolidadas, o mesmo não pode ser dito em relação a países em processo de construção democrática, como o Brasil. Argumentamos que, no Brasil, a cultura política juvenil está longe de apresentar as características de assertividade propostas pelos autores. Pelo contrário, e paradoxalmente, a despeito do avanço da dimensão procedimental da democracia e do surgimento de NTIC's, os jovens continuam a mostrar atitudes e comportamentos políticos típicos de sociedades onde prevalecem a lealdade imposta e a submissão ao regime formal de democracia. 
É nesse tipo de cenário que as atitudes e comportamentos em relação à democracia, por parte dos jovens, se estruturam. Essas duas dimensóes são centrais para avaliar o tipo de cultura política que se desenhará para o futuro não só da juventude, mas da sociedade em geral, uma vez que são os jovens que colocaram em prática conteúdos antigos ou novos de uma cultura política que resulta de um conflito social permanente. Não é surpresa, portanto, a persistência de valores, crenças e normas negativas entre os jovens, apesar dos avanços das NTIC's que, em tese, seriam instrumentos para a constituição de cidadãos mais críticos e participativos. Pensamos que a resposta a está indagação pode ser encontrada no processo de socializaçáo política dos jovens num sentido longitudinal.

O conceito de socialização se refere ao processo de internalização, por parte do indivíduo, das normas e valores políticos da sociedade. Trata-se, portanto, de um processo de aprendizagem que se realiza sob a influência de diferentes agências ao longo da vida do sujeito (ALMOND e VERBA, 1989; BAQUERO e BAQUERO, 2014). Não há convergência, entretanto, em relação a aspectos importantes desse processo, tais como: se é um processo estático ou dinâmico, quando começa e termina, qual o período em que acontece com mais intensidade, se as instituiçóes o influenciam ou não, qual a influência das diferentes agências e quais são seus agentes.

A literatura sobre socialização política a separa em duas dimensôes: resultados e processos. Da perspectiva de resultados, a socialização centra sua análise na estruturação dos valores políticos transmitidos de geração para a geração. $\mathrm{Na}$ dimensão de processo, a socialização é considerada um processo dinâmico e não necessariamente um processo de etapas que estabelece formas convencionais na formação de cidadãos. Neste sentido, outros fatores tais como crises econômicas ou políticas, o advento de novas formas de sociabilidade e a emergência de novas formas de comunicação poderiam estar influenciando um novo processo de socialização política e, consequentemente, uma nova cultura política juvenil.

Há um consenso de que, seja qual for a dimensão teórica utilizada, os valores, normas e crenças políticas internalizadas pelos jovens e transmitidas pelas principais agências de socialização política (família, escola, pares, mídia e internet) são centrais na estruturação de uma cultura política juvenil. O grau de democratização ou qualidade democrática apresentado por um regime político está, portanto, entrelaçado à história e aos fatores estruturais desenvolvidos e transmitidos ao longo do tempo pelas agências tradicionais e novas de socialização política (internet e redes sociais). 
84 | Marcello Baquero, Rute Baquero e Jennifer Morais

Esses novos agentes de socializaçáo política estariam produzindo novas atitudes e comportamentos políticos, resultantes da conjunção, exposição, comunicação e receptividade entre eles. Beck (1977), há três décadas desenhou um modelo de análise que mostrava que a exposição, comunicação e receptividade de uma pessoa à família, escola e grupos de amigos formatavam sua personalidade política.

Segundo o autor, até os quatro anos de idade, as crianças são totalmente dependentes dos pais em termos de emulação de comportamentos. A partir dessa faixa etária a influência da família, em virtude de suas primeiras experiências com a escola, diminui, estabelecendo uma equivalência com a influência familiar. Para Beck, a influência dos grupos de amigos assume centralidade na faixa etária dos 20 anos.

É nessa idade que a comunicação se torna essencial para criar grupos de referência com afinidades, no caso político, ideológicas, uma vez que a terceira característica da socialização política- a receptividade- solidifica a formação de comunidades sociais. Neste sentido, o grau de abertura ao processo de socializaçáo depende da proximidade das pessoas e/ou instituiçóes que socializam politicamente um jovem.

Ampliando o escopo de análise para o presente, poder-se-ia argumentar que a internet e as redes sociais conseguiram algo que era impensado há poucas décadas, isto é, a disponibilidade de um instrumento de comunicação virtual que propiciou ir além das comunidades sociais tradicionais que se restringiam a um pequeno grupo de conhecidos, para a formaçáo de comunidades virtuais compostas por milhares de indivíduos vinculados por interesses específicos. É nessa perspectiva que as NTIC's passaram a ser consideradas como poderosas agências de socialização, capazes de introduzir dispositivos mais eficientes na politização dos jovens.

Esse novo dispositivo de formação de identidades coletivas virtuais, se pressupóe, auxiliaria no fortalecimento democrático, uma vez que produziria cidadáos instrumentalizados, cognitiva e afetivamente, estimulando-os a uma participação mais concreta do que em períodos anteriores. Os jovens cidadãos passariam a avaliar de forma mais próxima, o impacto das açóes do governo na sua vida. Adquiririam um maior conhecimento sobre seus direitos e, sobretudo, tomariam conhecimento dos mecanismos disponíveis e necessários para transmitir suas demandas para o Estado. Teríamos, então, a presença de cidadãos assertivos e não submissos ao Estado. Se tal argumento fosse correto, estaríamos diante da possibilidade de romper com práticas políticas tradicionais pouco afeitas ao fomento democrático.

No entanto, os dados aqui examinados não permitem validar tal conclusão como será visto a seguir. 


\section{A dimensão empirica}

A literatura a respeito do processo de construção da cultura política no Brasil via socialização política tem, recorrentemente, apontado os efeitos deletérios que a ausência de motivação dos jovens para se envolver com a política pode ter na democratização. Sob essas circunstâncias, um primeiro indicador desse processo diz respeito ao grau de interesse que os jovens mostram por política. Se, de fato, estivesse em andamento um processo de institucionalização de comportamentos assertivos, esperar-se-ia que o interesse nos acontecimentos políticos fosse maior do que nas décadas de 1980 a 2000, nas quais, em média, $60 \%$ dos jovens não mostrava interesse por política. Ao mesmo tempo, para avaliar se as NTIC's influenciam ou não o grau de interesse, realizou-se um cruzamento entre essas duas variáveis apresentados no Gráfico 1.

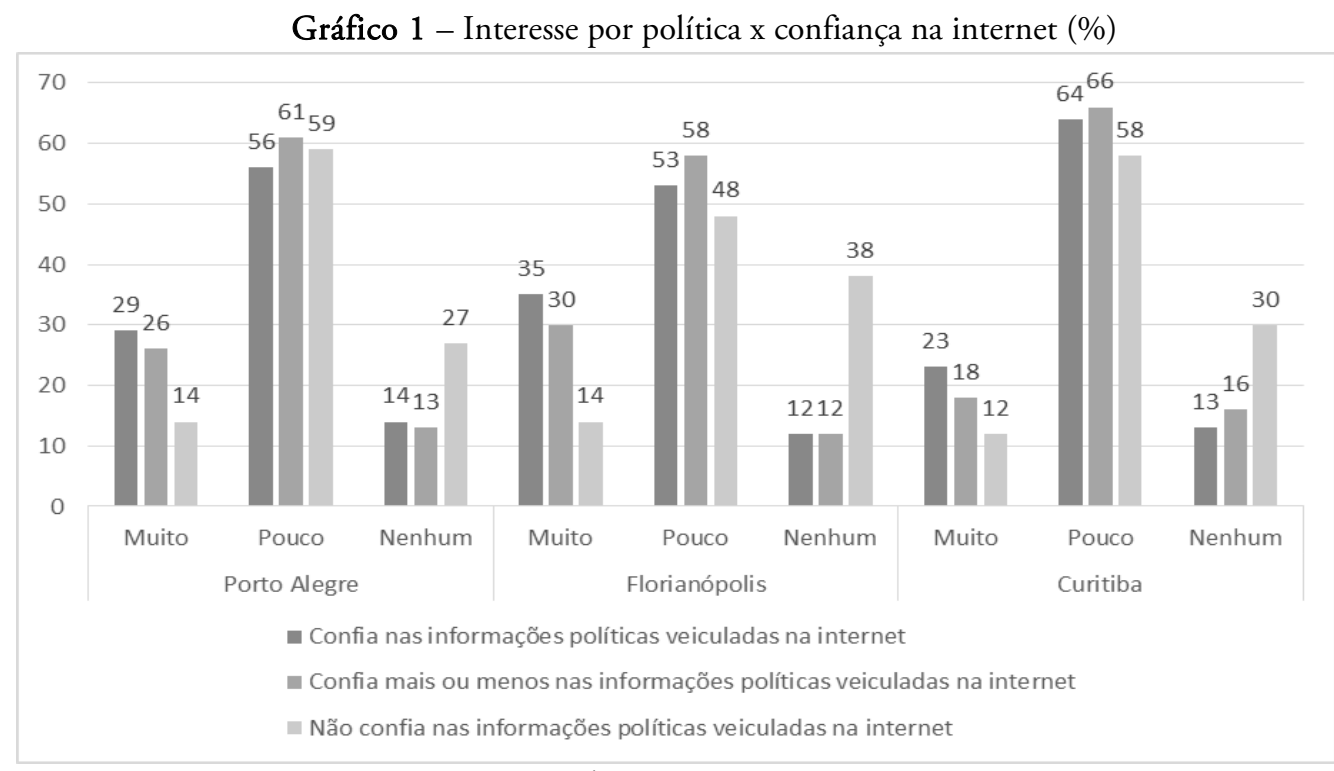

n POA = 690; $\mathrm{n}$ FLO = 571; $\mathrm{n}$ CUR $=774 /$ r POA = 0,001; $\mathrm{r}$ FLO = 0,000; $\mathrm{r}$ CUR = 0,001 Fonte: Nupesal, 2015 e 2016.

De forma geral, os dados do Gráfico 1 indicam que o interesse por política nas três cidades pesquisadas, continua a ser reduzido. Entretanto, há uma correlação significativa ( $\mathrm{p}$.05) entre confiança nas notícias divulgadas pela internet e o grau de interesse por política. Entre os que se interessam por política, observa-se uma tendência de confiar (29\% em Porto Alegre, 35\% em Florianópolis e 23\% em 
Curitiba) nas informaçóes políticas divulgadas pela internet. Já entre aqueles que se interessam pouco ou não se interessam, a média de desconfiança nas informaçóes divulgadas pela internet é elevada e dentro dos padróes tradicionais de desconfiança política (60\% em Porto Alegre, 53\% em Florianópolis e 62\% em Curitiba). O mesmo padrão se observa para os que não mostram interesse por política.

Há, portanto, uma associação entre confiança na internet e interesse por política, sugerindo que, gradualmente, os jovens mais interessados em assuntos políticos se voltam para a internet como fonte de informaçóes para estruturar suas atitudes políticas. Entretanto, em termos comparativos e longitudinais, no período de 2002 a 2016, a média de desconfiança na política (pouco 59\%, ou nenhum interesse $19 \%$ ) teve oscilaçóes pouco significativas (a grande maioria dos jovens continua a mostrar falta de interesse em acompanhar tais assuntos). Tal situação, acreditamos, pode ser compreendida com base na utilidade que os jovens dáo ao uso da internet. Estes dados estão na Tabela 1.

Tabela 1 - Motivação do uso da internet

\begin{tabular}{l|l|l|l}
\hline & Porto Alegre & Florianópolis & Curitiba \\
\hline Entretenimento & 35 & 28 & 37 \\
\hline Informaçáo & 6 & 11 & 9 \\
\hline Ambos & 59 & 61 & 54 \\
\hline Total & 100 & 100 & 100 \\
\hline
\end{tabular}

n POA = 690; n FLO = 571; n CUR = 774

Fonte: Nupesal, 2015 e 2016.

Passado algum tempo da existência da internet, em que a novidade inicial era a possibilidade de descobrir um mundo virtual desconhecido, por meio do acesso a informaçóes nunca antes imaginadas, esperar-se-ia que a juventude, dentro de um processo de desenvolvimento de assertividade, utilizasse esse dispositivo de forma estratégica para alavancar seus conhecimentos. De fato, as expectativas eram de que essas NTIC's produzissem jovens cidadáos politizados, entretanto, não parece ser o caso.

Estudos recentes, de natureza qualitativa, nos Estados Unidos, sobre como os jovens utilizam a internet, constataram que o uso depende da classe social (PUTNAM, 2014). Jovens das classes pobres utilizam, preponderantemente, a internet como entretenimento, enquanto os de classes mais abastadas a utilizam estrategicamente para aperfeiçoar sua formação e encontrar melhores oportunidades de avançar social e economicamente. Tal descoberta, para Putnam, denota a 
influência que a desigualdade social tem na forma como os jovens decodificam o mundo e se posicionam comportamentalmente nele.

Considerando esse resultado, é relevante avaliar se tal fenômeno também ocorre no Brasil. Os dados da Tabela 1 mostram, inicialmente, que a juventude acessa a internet pelas duas razóes $(\mathrm{m}=58 \%)$; porém, quando analisadas isoladamente as categorias se verifica que o estímulo principal é o entretenimento $(\mathrm{m}=33 \%)$ e não a busca de informaçôes $(m=8,6 \%)$. A seguir, examinamos, na Tabela 2 , a motivação do uso da internet por renda, com o objetivo de comparar com os resultados da pesquisa de Putnam.

Tabela 2 - Renda por motivação do uso da internet

\begin{tabular}{|c|c|c|c|c|c|c|c|c|c|c|}
\hline & \multicolumn{9}{|c|}{ Motivação do uso da internet } \\
\hline & & \multicolumn{3}{|c|}{ Porto Alegre } & \multicolumn{3}{|c|}{ Florianópolis } & \multicolumn{3}{|c|}{ Curitiba } \\
\hline & & Ent. & Inf. & Ambos & Ent. & Inf. & Ambos & Ent. & Inf. & Ambos \\
\hline \multirow{4}{*}{ Renda } & $\begin{array}{c}\text { Até } 1 \text { sal. } \\
\text { mín. }\end{array}$ & 41 & 18 & 41 & 45 & 25 & 30 & 54 & 8 & 38 \\
\hline & $\begin{array}{c}1 \text { a } 2 \text { sal. } \\
\text { mín }\end{array}$ & 51 & 3 & 46 & 32 & 12 & 52 & 38 & 9 & 53 \\
\hline & $\begin{array}{c}3 \text { a } 4 \text { sal. } \\
\text { mín }\end{array}$ & 39 & 5 & 57 & 26 & 10 & 63 & 34 & 7 & 59 \\
\hline & $\begin{array}{c}\text { Mais de } 5 \\
\text { sal. mín }\end{array}$ & 27 & 2 & 70 & 24 & 4 & 71 & 36 & 10 & 55 \\
\hline
\end{tabular}

n $\mathrm{POA}=690 ; \mathrm{n} \mathrm{FLO} \mathrm{=} \mathrm{571;} \mathrm{n}$ CUR = 774/ $\mathrm{r}$ POA = 0,000; $\mathrm{r}$ FLO = 0,00; $\mathrm{r}$ CUR = 0,048 Fonte: Nupesal, 2015 e 2016.

A comparação com o estudo de Putnam precisa ser relativizada, uma vez que, neste estudo, utilizamos renda como proxi de classe social, por parecer mais adequado à realidade brasileira. Os dados indicam que, de fato, os jovens de renda mais baixa (até dois salários mínimos) tendem a usar a internet mais como instrumento de entretenimento do que para adquirir informaçôes ( $\mathrm{m}=46 \% \mathrm{em}$ Porto Alegre, $39 \% \mathrm{em}$ Florianópolis e $46 \%$ em Curitiba). Optamos por colocar um ponto intermediário para aqueles com renda até quatro salários mínimos, onde começa a se observar um leve declínio em relação ao uso da internet para entretenimento (39\%, 26\% e 34\%, respectivamente). Para aqueles com mais de 5 salários mínimos há uma redução significativa $(27 \%, 24 \%$ e $36 \%$ respectivamente). Portanto, os dados sugerem que, quanto maior a renda, maior o uso da internet como fonte de informaçóes $(2 \%, 4 \%$ e $10 \%$, respectivamente). 
88 | Marcello Baquero, Rute Baquero e Jennifer Morais

Esse resultado, do ponto de vista da socialização política e da construção de uma cultura política juvenil, alerta que, antes de se pensar na internet como catalisadora de uma cultura política dos jovens de natureza assertiva, é necessário visualizá-la como uma ferramenta sofisticada de entretenimento.

Parece-nos que o uso da internet, nessa direção, se constitui um dispositivo acessível para obter informaçóes, ao qual os jovens recorrem na maior parte do tempo, conforme os dados da Tabela 3, influenciando sua forma de pensar (Tabela 4), mas que não impacta na dimensão de comportamento presencial, considerado essencial no processo de fortalecimento da democracia (Tabela 5).

Tabela 3 - Quando quer saber mais sobre assuntos políticos, com que frequência você se informa pela internet?

\begin{tabular}{l|l|l|l}
\hline & Porto Alegre & Florianópolis & Curitiba \\
\hline Sempre & 59 & 59 & 54 \\
\hline Ás vezes & 31 & 33 & 34 \\
\hline Nunca & 10 & 8 & 12 \\
\hline Total & 100 & 100 & 100 \\
\hline
\end{tabular}

n POA $=690 ;$ n FLO = 571; n CUR $=774$

Fonte: Nupesal, 2015 e 2016.

Tabela 4 - Você acha que a internet influencia na sua forma de pensar?

\begin{tabular}{l|l|l|l}
\hline & Porto Alegre & Florianópolis & Curitiba \\
\hline Sempre & 43 & 44 & 44 \\
\hline Às vezes & 42 & 40 & 39 \\
\hline Náo & 16 & 16 & 17 \\
\hline Total & 100 & 100 & 100 \\
\hline
\end{tabular}

n $\mathrm{POA}=690 ; \mathrm{n}$ FLO $=571 ; \mathrm{n}$ CUR $=774$

Fonte: Nupesal, 2015 e 2016.

Tabela 5 - Você acha que a internet influencia na sua forma de agir?

\begin{tabular}{l|l|l|l}
\hline & Porto Alegre & Florianópolis & Curitiba \\
\hline Sempre & 27 & 29 & 27 \\
\hline Ás vezes & 37 & 38 & 41 \\
\hline Náo & 36 & 33 & 32 \\
\hline Total & 100 & 100 & 100 \\
\hline
\end{tabular}

n POA = 690; $\mathrm{n}$ FLO = 571; $\mathrm{n}$ CUR $=774$

Fonte: Nupesal, 2015 e 2016. 
Quando as pessoas mostram uma incongruência entre o que pensam e como agem, o resultado geralmente se manifesta na institucionalizaçáo de uma cultura política híbrida, na qual a participação política é episódica e reduzida. É isto que se observa ao analisarmos a percepção dos jovens em relaçáo ao principal problema do país e sua participação nas manifestações de 2013 (Tabela 6).

Tabela 6 - Participação nas manifestações de 2013 x Principal problema do país (\%)

\begin{tabular}{c|c|c|c|c|c|c|c}
\hline \multirow{2}{*}{} & \multicolumn{6}{c}{ Participaçáo nas manifestaçóes de 2013 } \\
\cline { 3 - 8 } \multicolumn{2}{c|}{} & \multicolumn{2}{c|}{ Porto Alegre } & \multicolumn{2}{c}{ Florianópolis } & \multicolumn{2}{c}{ Curitiba } \\
\cline { 3 - 8 } \multicolumn{1}{c|}{} & Sim & Náo & Sim & Náo & Sim & Náo \\
\hline \multirow{4}{*}{$\begin{array}{c}\text { Principal } \\
\text { problema } \\
\text { do país }\end{array}$} & Inflaçáo & 18 & 82 & 0 & 100 & 4 & 96 \\
\cline { 2 - 8 } & Desemprego & 11 & 89 & 19 & 81 & 8 & 92 \\
\cline { 2 - 8 } & Saúde & 11 & 89 & 21 & 79 & 8 & 92 \\
\cline { 2 - 8 } & Pobreza & 7 & 93 & 11 & 89 & 0 & 100 \\
\cline { 2 - 8 } & Corrupçáo & 23 & 77 & 20 & 80 & 10 & 90 \\
\cline { 2 - 8 } & Moradia & 20 & 80 & 0 & 100 & 0 & 100 \\
\cline { 2 - 8 } & Transporte & 25 & 75 & 0 & 100 & 0 & 100 \\
\cline { 2 - 8 } & Educaçáo & 21 & 79 & 23 & 77 & 14 & 86 \\
\cline { 2 - 8 } & Outro & 17 & 83 & 18 & 82 & 18 & 82 \\
\hline
\end{tabular}

$\mathrm{n} \mathrm{POA}=690 ; \mathrm{n} \mathrm{FLO}=571 ; \mathrm{n}$ CUR $=774 / \mathrm{r} \mathrm{POA}=0,423 \mathrm{r}$ FLO $=0,989 \mathrm{r}$ CUR $=0,546$ Fonte: Nupesal, 2015 e 2016.

O que se constata na Tabela 6 é que, da mesma forma que, no passado, os jovens não mostram predisposiçóes a se envolver em assuntos políticos. $\mathrm{Na}$ média, mais de $75 \%$ deles náo participou dos protestos de 2013 , embora a maioria tenha acompanhado pelas redes sociais. Para aqueles que participaram, assim o fizeram por razóes conjunturais e que estavam visíveis na época (corrupção, moradia, transporte e educação). Também cabe lembrar que a pesquisa em Curitiba foi realizada em maio de 2016, enquanto, em Florianópolis, foi em setembro de 2015 e Porto Alegre em março de 2015.

\section{À guisa da conclusão}

Os dados examinados neste artigo permitem avaliar o efeito que o surgimento da internet e das redes sociais tem na juventude no Sul do Brasil e, consequentemente, o que se pode esperar em termos de constituição de uma nova cultura política. Não se pode negar que os jovens, no presente, utilizam as NTIC's para estabelecer comunidades virtuais e identidades coletivas com base em aspectos ou demandas pontuais. 
Do ponto de vista da estruturação de uma nova cultura política juvenil fruto do papel socializador da internet, os dados aqui examinados não confirmam tal cenário. Pelo contrario, ao comparar com dados sobre atitudes, comportamentos na arena política, se constata que os jovens continuam a serem influenciados pelas agências tradicionais de socialização política (escola, família e pares), tendo a internet um papel mais moderado, uma vez que a grande maioria dos jovens utiliza esta ferramenta para propósitos de entretenimento e não de informação que possibilite ampliar o leque de possibilidades, por exemplo, de conseguir oportunidades de emprego.

No que se refere a padrôes de participação política, os dados indicam que, na perspectiva de Easton (1965), a respeito de apoio difuso e apoio específico, os jovens entrevistados nas pesquisas se enquadram claramente nessa dicotomia. Se, por um lado, respondem que a internet pode se um instrumento poderoso de participação política, e a maioria acompanha eventos dessa natureza, quando indagados sobre sua participação presencial, a grande maioria, à semelhança de um padrão tradicional, não mostra predisposiçôes de envolvimento presencial.

Subjacente a essas observaçóes nosso argumento é de que as interaçóes digitais entre os jovens nas cidades pesquisadas parecem ser utilizadas como uma extensão dos agentes tradicionais de socialização política, incorporando os valores, normas e crenças já estabelecidas nessas interações. Em tal cenário, o tipo de cultura política que se desenha tende a seguir o mesmo padrão de relaçóes construídas com amigos, parentes e atitudes perante a mídia e outros dispositivos de transmissão de informaçóes, ou seja, uma cultura política hibrida e incongruente entre atitudes e comportamento.

Desse modo, se a participação e a organização de uma sociedade auxiliam para o fortalecimento democrático, os dados aqui analisados da juventude no Sul do Brasil sugerem que a internet $\mathrm{e}$ as redes sociais náo estão catalisando novos padróes mais assertivos de cultura política. Pesquisas realizadas desde a década de noventa constataram uma juventude passiva, indiferente e anomica em relação a assuntos políticos. Isso não significa reconhecer que, em determinados momentos, o papel dos jovens foi central para alcançar objetivos históricos significativos, como foi o caso dos "caras pintadas" e do envolvimento deles em manifestaçóes como as de 2013. Tais posturas, entretanto, não modificaram a estrutura da cultura política que, apesar desses surtos importantes de participação presencial, manteve os padróes tradicionais de engajamento político. Tratava-se, portanto, de participação episódica e não transformadora dos padrôes tradicionais de envolvimento político. 
O baixo grau de envolvimento dos jovens em quaisquer tipos de associaçóes, desde a escola, o bairro, a comunidade, até a arena política não têm possibilitado que se institucionalize um aprendizado político (STOLLE e HOOGHE, 2002, p.3).

Por causa desse cenário, atribuíu-se um papel central à emergência da internet e as redes sociais como mecanismos que alavancariam as interaçóes entre os jovens, agindo como uma nova agência de socialização política, que resultaria na formação de comunidades virtuais que institucionalizariam outra forma de participaçáo política mais efetiva e capaz de transformar aquilo que era repudiado na política. No entanto, as interações continuam a ser diluídas, abstratas, que resultam em ações episódicas. A contradição, todavia, está no fato dos jovens acharem importante participar, sem que isso se concretize na sua prática. Assim, os dados apontam ainda para a existência de um déficit no processo de socialização política dos jovens brasileiros.

A situação da juventude brasileira, pautada por obstáculos, impasses e conflitos que dificultam o desenvolvimento de redes de confiança, cooperaçóes e reciprocidade entre os jovens, coloca as ciências sociais e, em especial, a ciência política diante do desafio de criar alternativas e estratégias que permitam transcender os limites impostos pela crise atual, de forma a permitir o empoderamento dos jovens, estimular a geração de capital social e promover a participação política e a socialização para a democracia.

Os resultados desta investigação evidenciam que são incipientes, no Brasil, pesquisas referentes à relação entre as NTIC's e o tipo de cultura política que se está estruturando. Também foi observada a deterioração de algumas redes sociais, contraditoriamente à aparente revitalização da vida política e comunitária em nível nacional.

Observou-se, ainda, que a socialização política via redes sociais não vem incentivando, nos jovens, sentimentos e comportamentos relacionados à importância da frequência de participação em atividades associativas e políticas. Os assuntos de política não despertam o interesse dos jovens brasileiros. A televisão, por sua vez, continua a ser a principal fonte de informação dos jovens e exerce maior influência sobre as atitudes políticas.

Contribuem para esses efeitos perversos os efeitos conjunturais das crises econômicas e de corrupção, bem como os efeitos estruturais indicados por uma cultura política híbrida e de desconfiança entre os jovens, que incide sobre a socialização destes, de forma a não permitir a ampliação dos índices de participação política presencial. Assim, tampouco estão contribuindo suficientemente para 
revitalizar ou recriar espaços democráticos, para estimular novas formas de cooperação, organização e de participação política, bem como para ampliar a esfera de participação na sociedade civil.

Marcello Baquero é Doutor em Ciência Politica. Professor Titular do Programa de Pós-Graduação em Ciência Política da Universidade Federal do Rio Grande do Sul (UFRGS). E-mail: marcelo.baquero@ufrgs.br.

- Rute Vivian Angelo Baquero é Doutora em Educação. Pesquisadora do Núcleo de Pesquisa sobre América Latina (NUPESAL) da UFRGS. E-mail: rutevivianb@gmail.com.

- Jennifer Azambuja de Morais é Doutoranda do Programa de PósGraduação em Ciência Politica da UFRGS e Pesquisadora do NUPESAL. E-mail: jennifer.amorais@gmail.com.

\section{Referências}

AGUIAR, Sonia. Redes sociais na internet: desafios à pesquisa. XXX Congresso Brasileiro de Ciências da Comunicação, Santos, 29 de agosto a 2 de setembro de 2007.

ALMOND, Gabriel; VERBA, Sydnei. The civic culture revisited. Califórnia: Sage Publications, 1989.

$B A Q U E R O$, Rute; BAQUERO, Marcello. Formaçáo cidadã de jovens no contexto de um regime democrático híbrido. Revista Debates, v. 8, p. 59-82, 2014.

BAQUERO, Marcello; MORAIS, Jennifer. A internet produz cidadãos politicamente sofisticados? A construçáo de uma cultura política juvenil no Sul do Brasil. Apresentado no $39^{\circ}$ Encontro Anual da ANPOCS. Caxambu/MG. Outubro 2015.

BAQUERO, Marcello; MORAIS, Jennifer. The dark side of social networking. The internet and (des) politization of the Brazilian youth. Apresentado no Latin American Studies Association 2016. Nova Iorque. 2016.

BECK, Paul A. The Role of Agents in Political Socialization. In: RENSHON, Stanley A (org.). Handbook of Political Socialization: Theory and Research. Nova Iorque, Londres: The Free Press, 1977.

CAPELLA, Joseph N.; JAMIESON, Kathleen Hall. Spiral of Cynicism. The press and the public good. New York/Oxford: Oxford University Press, 1997.

CASTELLS, Manuel. A galáxia da internet: reflexôes sobre a internet, os negócios e a sociedade. Rio de Janeiro: Jorge Zahar, 2003.

CASTELLS, Manuel. A Sociedade em rede. São Paulo: Paz e Terra, 2007. 
DAHL, Robert. Sobre a Democracia. Brasília: Editora Universidade de Brasília, 1992.

DALTON, Russell; WELZEL, Christian, Welzel. Political Culure and Value Change. In.: DALTON, Russell; WELZEL, Christian (org.). The civic culture transformed. Cambridge Universit Press. 2014.

FUNDAÇÃO TELEFÔNICA VIVO. Conectados e Engajados. Publicado em 11 de fevereiro de 2014. Disponível em: http://blog.fundacaotelefonica.org.br/. Acessado em 20 de mai. 2016.

GARTON, Laura; HAYTHORNTHWAITE, Cardine; WELLMAN, Barry. Studying Online Social Networks. Journal of Computer Mediated Communication, n. 3, v. 1, 1997. Disponível em <http://www.ascusc.org/jcmc/vol3/issue1/garton.html>. Acesso em: 13 junho 2016.

IBGE. Instituto Brasileiro de Geografia e Estatística. Censo 2010. Disponível em $<$ http://www.ibge.gov.br/home/>. Acesso em 9 de ago. 2016.

INGLEHART, Ronald. The Silent Revolution: Changing Values and Political Styles among Western Publics. Princeton: Princeton University Press, 1977.

MACHADO, Joicemegue Ribeiro; TIJIBOY, Ana Vilma. Redes Sociais Virtuais: um espaço para efetivação da aprendizagem cooperativa. Novas Tecnologias na Educação, v. 3 n. 1, maio, 2005.

MATOS, Heloiza. Capital social, Internet e TV: Controvérsias. Organicom, ano 5, n. 8, 2007. p. 2435.

MERVIN, David. The news media and De- mocracy in the United States. In: RANDALL, Vicky (ed.). Democratization and the Media. London/Portland: Frank Cass, 1998.

MOISÉS, José Álvaro. Os brasileiros e a democracia: bases sócio-políticas da legitimidade democrática. São Paulo, Ática. 1995.

MOISÉS, José Álvaro. Cultura Política, Instituiçóes e Democracia Liçōes da Experiência Brasileira. Revista Brasileira de Ciências Sociais, São Paulo, v. 23, n. 66, 2010. Disponível em: <http://www.scielo.br/scielo.php?pid=S0102-69092008000100002\&script=sci_arttext $>$. Acesso em: 10 ago. 2016.

NEGRINE, Ralph. The Communication of Politics. London/Thousand Oaks/New Dehli: Sage, 1996.

NEWTON, Kenneth. Mass media effects: mobilization or media malaise? British Journal of Political Science, v. 29, n. 4, 1999.

NORRIS, Pippa. On Message: communicating the campaign. London/Thousand Oaks/New Dehli: Sage, 1999.

NUPESAL. Banco de Dados do Núcleo de Pesquisa sobre América Latina. Pesquisa Democracia, mídias e capital social: Um estudo comparativo de socialização política dos jovens no Sul do Brasil. Porto Alegre. 2015.

NUPESAL. Banco de Dados do Núcleo de Pesquisa sobre América Latina. Pesquisa Democracia, mídias e capital social: Um estudo comparativo de socialização política dos jovens no Sul do Brasil. Florianópolis e Curitiba. 2016.

PATTERSON, Thomas. The Mass Media Election: how Americans choose their President. New York: Praeger, 1980.

PATTERSON, Thomas. Time and News: the media's limitations as an instrument of Democracy. International Political Science Review, v. 19, n. 1, 1998.

PRENSKY, Marc. Digital Natives, Digital Immigrants. MCB University Press, 2006. Disponível em: http://www.marcprensky.com/writing/Prensky\%20\%20Digital\%20

Natives,\%20Digital\%20Immigrants\%20-\%20Part1.pdf>.Acessado em 8 jul. 2016. 
94 | Marcello Baquero, Rute Baquero e Jennifer Morais

PRIMO, Alex. Interação Mediada por Computador: A comunicação e a educação a distância segundo uma perspectiva sistêmico-relacional. Tese de Doutorado. Apresentada ao Programa de PósGraduação em Informática na Educação em março de 2003.

PUTNAM, Robert. Tuning in, Tuning out: the strange disappearance of social capital in America. PS - Political Science and Politics XXVIII (4), 1995.

PUTNAM, Robert. Our kids. The American dream in crisis. New York: Simon \& Schuster, 2014.

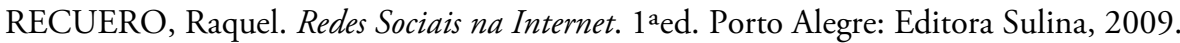

RHEINGOLD, H. La Comunidad Virtual: Una Sociedad sin Fronteras. Barcelona: Gedisa Editorial, 1995.

SALES, Celecina de Maria Veras. Juventudes, novas experimentaçóes, conexóes e interatividade. Texto apresentado no XV Congresso Brasileiro de Sociologia, Curitiba/ PR, jan. 2011.

SCHWARTZMAN, Simon; DURHAM, Eunice Ribeiro; GOLDEMBERG, José. A Educação no Brasil em uma perspectiva de transformação. Documento de Trabalho 5/93. In: PURYEAR, Joseph, BRUNNER, José Joaquín (org.). Educación, Equidad y Competitividad Económica en las Américas: Un Proyecto del Diálogo Latinoamericano, v. 2. p. 51-100. Washington: Organização dos Estados Americanos, 1995. (Coleção INTERAMER n. 40, série educativa).

SEN, Amartya. Development as Freedom. Oxford: Oxford University Press, 1999.

SHIN, Doh C. Democratization: Perspectives From Global Citizenries. Center for the Study of Democracy, 2006. Disponível em https://escholarship.org/uc/item/5b49k5rc. Acessado em 12 de julho de 2016.

TARGINO, Maria das Graças. Midiatização da informação: aplicaçôes e implicações.. In: BORGES, J.; SOUSA, M. I.; PEDROZA, F.. (Org.). Mundo digital: uma sociedade sem fronteiras?. 1ed.João Pessoa: Ideia, 2014, v. 1, p. 105-126.

THOMPSON, William E.; HICKEY, Joseph V. Society in Focus: An Introduction to Sociology. Prentice Hall PTR, 2011.

TOKMAN, Victor E. Jóvenes, formación y empleabilidad. VIII Conferencia Iberoamericana de Ministros de Juventud. Buenos Aires, 31 de julho a 3 de agosto, 1996.

Texto recebido em 25 de julho de 2016. Aprovado em 25 de agosto de 2016. 